Original Research Paper

\title{
Design IoT Based Smart Electricity Power Saving University: Analysis from a Lecture Hall
}

\author{
Shanmuganathan Vasanthapriyan and Viduni Randima \\ Department of Computing and Information Systems, Sabaragamuwa University of Sri Lanka, \\ Belihuloya, Sri Lanka
}

Article history

Received: 05-05-2019

Revised: 30-07-2019

Accepted: 08-08-2019

Corresponding Author:

Vasanthapriyan, S.

Department of Computing

and Information Systems,

Sabaragamuwa University of

Sri Lanka, Belihuloya 70140 ,

Sri Lanka

Email: priyan@appsc.sab.ac.lk

\begin{abstract}
Managing and controlling the electricity consumption in a productive manner is a red hot topic in today's world. Many countries have considered this problem and they have suggested automate systems to overcome this problem. Since, Sri Lankan has not used such kind of automated system to control the electricity power consumption, our system will be a suitable solution for that. Today, IoT is a technological paradigm that is used to build such kind of automates systems. In our proposed system also, IoT and sensor technologies are used. It is a system that responds to human presence and provides related actions according to the human occurrences area environmental condition. It is control the electric devices such as lights, fans and AC in the lecture hall according to temperature and light intensity values that detect by the sensors. We used Kinect sensor to detect human presence. DHT22 and LDR sensors were used respectively to sensor the temperature, humidity and light intensity of human occupant area. Arduino- mega board was used to control the DHT22 and LDR sensors. In the research process we found the comfortable temperature and light intensity values that suitable for lecture hall and used those values to implement the prototype. Also, it provides real-time information such as current environmental condition of specific place and relevant messages including actions that need to take by using website. The main objectives of this research are reduce the wastage of electric power and provide suitable IoT based solution for reduced the electric power consumption.
\end{abstract}

Keywords: Smart Class Room, IoT, Power Saving Class Room

\section{Introduction}

The increase in demand for electricity power day by day, leads to the power crisis in the world. Rapid development of technology, industrial development and rapid urbanization also caused to increase the demand for electrical power to a huge extent. Another reason for increasing the electricity demand is the lack of natural resources that are used to generate electrical power. Today many countries use natural resources like Oil, Hydroelectric, Gas and coal to generate electricity. The choice of electricity production form depends on each country's economic viability, demand and region. But the problem is those resources cannot reproduce.
So in the future, there will be a shortage of natural resources that are used to produce electricity power.

The End of Fossil Fuels (2019) reported that a resource that is used to produce electrical power is one of the most critical problems in the world. Every year over 11 billion tons of oil is taken from fossil fuels. According to calculations of usage of oil resources, all the oil deposits last for only 53 years. Gas reserves could be finished in just over 52 years. Coal reserves could also be gone in 150 years. So there will be a huge problem because of lack of resources when producing electric power in the future.

Another problem that occurs when producing electricity is environmental problems. Lack of resources 
also causes to unbalance nature. Generating electric power using oil, gas and coal cause to emit $\mathrm{CO}_{2}, \mathrm{CO}$ and harmful gases that harm the ozone layer. Those gases also pollute the air in the environment. It also causes to climate change, global warming and human diseases such as lung cancers and different kinds of other lung diseases, headaches, incapacitation, unconsciousness, vertigo double vision etc.

Another problem is the cost to produce electricity. Capital expenditure of generating electricity using coal, gas and hydroelectric power is very high. Besides, people waste electric power in unnecessary ways. They fail to switch off the electric devices. This leads to excessive power consumption. So, it increases their electricity bill (Pingle et al., 2016).

To overcome the above mentioned problems proper solution is a needy thing. There are many solutions that have been provided by different researchers. Many solutions are based on the IoT. IoT is a new technology trend that many people use to solve their problems in an effective and efficient manner. Remotely monitoring electrical energy is one of the functions that IoT can perform (Del Ama Gonzalo et al., 2017). Providing realtime data is also another benefit of IoT. IoT with Web based electrical energy monitoring system is also one solution that can be used for electricity consumption problems. Demand response systems, smart grids, sensor based solutions are the most popular solutions today (Gonzalez et al., 2014). IoT can also be used to pattern recognizing, future prediction and decision making.

Universities in the world also now consider about reducing the unnecessary electricity consumption that happens in universities. The Sabaragamuwa University of Sri Lanka has not considered how to control the unnecessary electricity consumption happening in the university. Students leave lecture halls without switching off the electric devices in the lecture hall. There is no electricity monitoring system and controlling systems like in the most of the universities in the world. So, it needs a relevant solution to overcome the problem of electricity power waste in the university.

In this research we propose a system to overcome the problems above mentioned. The proposed system control the electric equipment according to human presence and environmental condition of the human occupied area. In existing systems, when a person enters the room, all the devices like fans and lights are turned on. If there are only a few people in the room or hall and if all the electric devices are working, it leads to unnecessary electric power waste. Also, in the existing systems PIR sensor is used to detect human. But PIR responds only for human motion. If there is no motion, it cannot control the devices in a specific area. To avoid such situations, we used Kinect sensor to detect humans. And DHT22 and LDR are used to detect environmental condition.

Research objectives that focused on are:

1- Reducing the wastage of electricity in Faculty of Applied Sciences, Sabaragamuwa University of Sri Lanka

In the faculty, electricity consumption occurs in various ways. So, to study the current situation of the faculty and find out how unnecessary electricity consumption happens in the faculty. To search what measures that can be used to solve the problem. According to previous studies as well as the current situation of the faculty, the purpose is to implement novel and suitable solution that can reduce the faculty's electricity consumption

2- Proposed IoT based electricity consumption solution for Faculty of Applied Sciences, Sabaragamuwa University of Sri Lanka

IoT is the most preferable technology that can manipulate to solve the problem of unnecessary electricity consumption. Previous research studies also prove that IoT related solutions are the most preferable. IoT also facilitates real-time information providing, decision making ability and automating the whole system (Chaudhari et al., 2016). So provide IoT based solutions to optimize the electricity consumption, by studying the existing research solutions and purpose novel solution that appropriate to faculty of Applied Sciences, Sabaragamuwa University of Sri Lanka is the second objective

\section{Literature Review and Related Works}

This section describes the related research findings and solutions that are related to electricity consumption.

The growth of sensor network provided facilities such as meter and store electricity consumption data virtually in real time (Matsui and Yamagata, 2014). Each and every sensor is connected to the communication network and provided various type of important data and send them to a central data center. This technology is recently used in Building Energy Management Systems (BEMS) (Singh et al., 2018) and Home Energy Management Systems (HEMS) (Matsui and Yamagata, 2014). Those systems provide information such as behavioural changes that occur in electricity conservation.

The economy of any country generally hangs on the energy utilization in different sectors of science and technology (Lakra et al., 2016). So energy consumption is an important issue in every country. Universities are also a considerable place that energy consumption can occur. Universities in developing countries mostly use manual switching system for electrical applications like light and fans. Often students forget to turn off the switches when leaving the lecture hall, public places, labs etc. This causes electricity wastage. Therefore, an automated system that 
can control the electric appliances is the best solution for that. IoT appliances such as wireless sensors, networked systems and monitoring systems can control energy consumption in the university without any human intervention (Lakra et al., 2016).

Research Smart energy in university is the most important thing is the sound management of building energy consumption (Jin et al., 2014). To manage buildings IoT is a needy thing. Because building- wide sensors management, collects the data, analyze, pattern recognition and prediction, as well as energy optimization and can do through using IoT (Bhushan et al., 2018). Heating, ventilation, air condition controlling are vital aspects that should be considered in the university (Minoli et al., 2017). IoT is not limited to one floor, time of day or seasons. So, using IoT can control the HVAC. Pan et al. (2014) stated that IoT based sensor lightning, remote control services, management of energy peripheral, Building-related surveillance/security lead to smart energy in university.

Lakra et al. (2016) stated that the Aligarh Muslim University, India has a purposed system that can automatically ON/OFF when a person came to the near the sensor area. Researchers are able to control electricity consumption according to the occupancy.

Lestari et al. (2017) reported that remotely monitoring the electrical energy is one of the functions that IoT can perform. Providing real-time data is also another benefit of IoT. IoT with Web based electrical energy monitoring system is also one solution that can be used for electricity consumption problems. Guiqing et al. (2012) said that "In the intelligent building fields, we have introduced the IoT technology to manage and control all kinds of building electrical equipment. The IoT for Building Electrical Equipment (IOTBEE) has established an effective way for safety monitoring and energy saving of the building electrical equipment. The IOTBEE can realize the interconnection of thingsbuilding electrical equipment, so how to involve various building electrical equipment into this network conveniently has become a key factor affecting the development of IOTBEE".

Ketchman et al. (2018) described that Building energy assessment resource (BEAR) is another solution that is used for electricity consumption. BEAR is mainly used for reducing energy consumption and cost of small commercial buildings by using limited resources. Researchers have selected two commercial enterprises for the study. Smart meters were installed in every plug and data collected using ZigBee network protocol. Each appliance's electricity consumption records were collected to the data management and visualization program. Bootstrap analysing is used to analyse the data sensitively. Finally the energy contour plot is developed by using Minitab software.
Jiang et al. (2013) expressed that Demand Response (DR) in smart grid also affected electricity consumption. It is an efficient way that user can respond according to electricity price and schedule. It provides wise and economically important information related to electricity consumption. Authors have been considering different pricing schemes. The study proposed scheme is mainly based on Nash Bargaining Solution (NBS) from cooperative game theory. First, they used a cooperative model to maximize net profit by using Practical Swarm Optimization (PSO) algorithm. Further authors proposed a cooperative model to NBS from game theory to maximize net profit. It also motivates users to the used utility in the company expect. Finally, authors proved that they reduced electricity consumption Peak-toAverage Ratio (PAR) for utility company.

Singh et al. (2018) reported that, according to the life cycle cost analysis and cost of conserved electricity, proposing the retrofit alternatives is another solution. A survey was conducted for an Indian urban housed to collect the data according to research. As reference authors have used "Guide for Conducting Energy Efficiency Potential Studies", which is provided by U.S. Environmental Protection Agency (EPA) to study the technical and economic importance of the electricity saving in the Indian urban households. Authors had used two equations to calculate the technical potential of electricity saving and two equations were included in the EPA guidelines. The economic potential was calculated by using Life Cycle Cost (LCC) analysis equation. Equation included investment cost, operational cost and rate of interest, consumer discount rate and life expectancy of equipment. According to the result interest rate and discount rate were 6 and $10 \%$ respectively. Also, Electricity price was seven rupees for $\mathrm{kWh}$. Another parameter that authors used was a Cost of Conserved Electricity (CCE). Using the result of those equations authors have purposed suitable retro fitment in order to achieve electricity saving.

Wei et al. (2016) proposed IoT based communication framework is another solution that can be used for managing the electricity consumption. To reduce energy consumption communication between interoperable systems is an important thing. To implement a common information model and provide additional attributes to the communication model, integrating the system with Facility Smart Grid Information Model (FSGIM) is one solution that authors have suggested. In that study authors have used open network protocols such like 6LoWPAN, IPv6 and CoAP to implement the network of communication model.

Another system is to control the electricity power using the Campus Card of each student (Jabeen and Kumar, 2016). Here they used Ethernet, RF wireless communication technology, PIR and LDR sensors to implement the system (Jabeen and Kumar, 2016). 


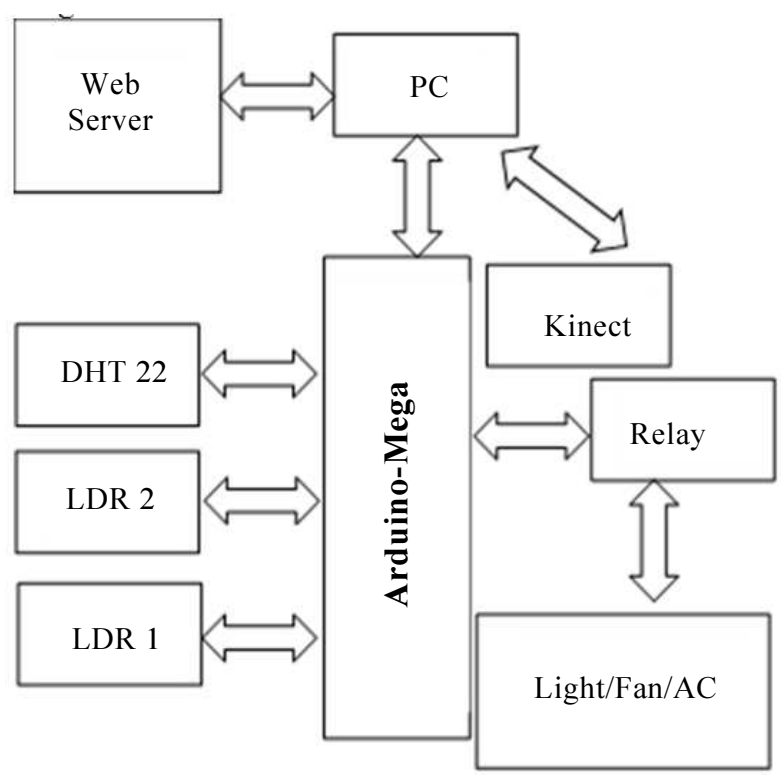

Fig. 1: System design

\section{Proposed System Design}

The purpose system can control the manual system without human intervention and it also helps to save the power and cut-off the expenditure. The system used sensor technologies and IoT to control the manual system.

Proposed system includes two main parts:

1. Sensors to detect human and condition of the place

2. IoT to provide the real time information and decision making

In the first part, the system detects the human and check lightning condition of the place when a person is presented. Then sends condition information to take further decisions. Then checks the humidity and temperature level of the place and activates the devices needed. If the temperature level is high the system automatically turns on the air conditioner or the fan.

In the second part, server takes the information given by the sensors and provide decisions. As an example, If the lecture hall has enough daylight it gives a message to occupants such as "Open the curtains!". Also, it provides details of working devices in a specific place.

The proposed design uses Arduino Mega board to connect to LDR, DHT22 sensors and relay modules. The Kinect sensor is used to detect humans. Arduino board and Kinect connected via PC and PC generate real time information by the help of web server and network connection. Figure 1 shows the proposed system design.

According to design architecture, the process of proposed system is described by Fig. 2 .

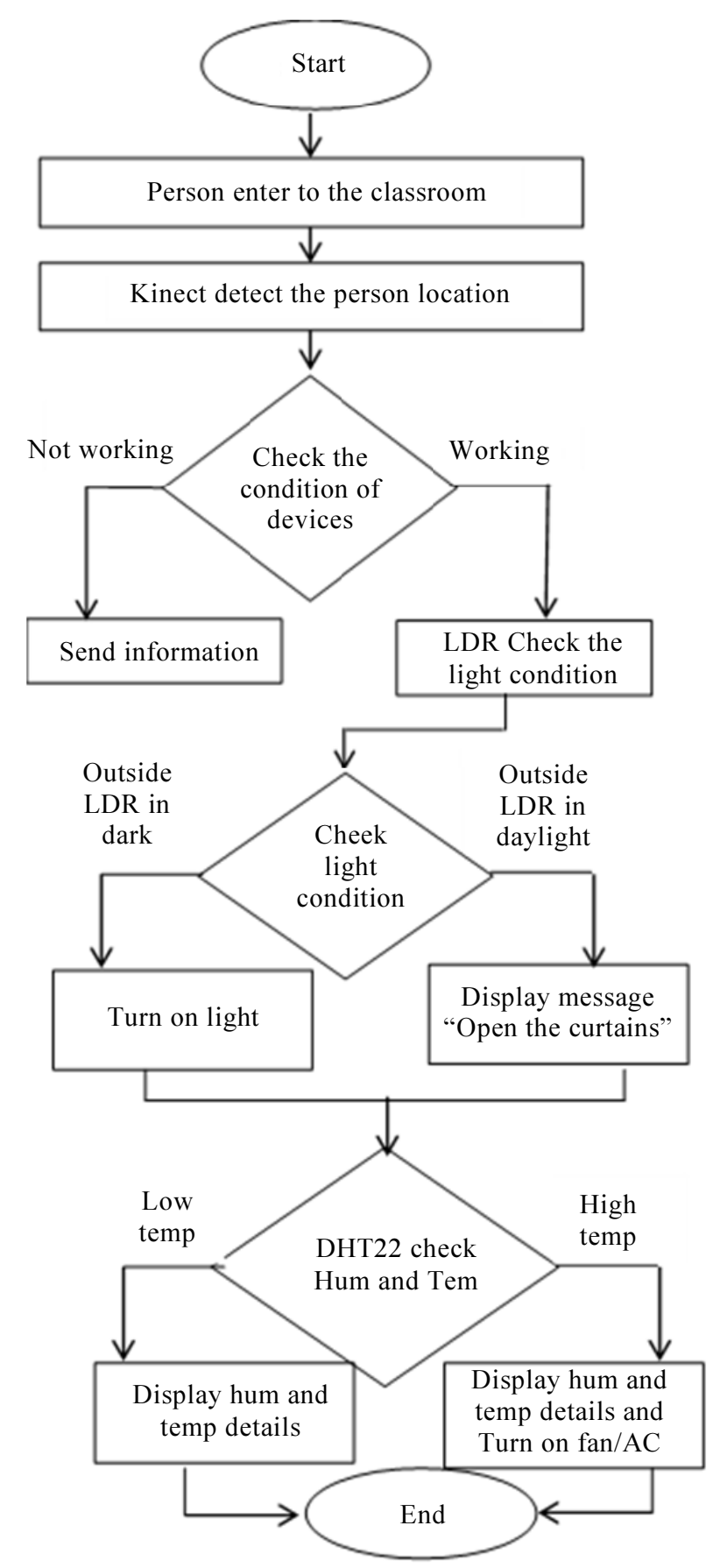

Fig. 2: Process of proposed system

\section{Methodology}

In this section, we explain the system implement procedure.

\section{Define the Comfortable Zone for Lecture Hall}

In order to define comfortable zone, we gather some data in order to define comfortable temperature value and 
light intensity values. To collect those data we used 25 students' responses under five conditions. There are:

1. Lecture hall without turn on lights and fans

2. Turn on 2 lights and 1 fan

3. Turn on 2 lights and 2 fans

4. Turn on 4 lights and 1 fan

5. Turn on 4 lights and 2 fans

We provided simple questionnaire to each students to fill out how they feel about the current condition in the lecture hall. They have to answer about how they feel about the temperature and light intensity in the lecture hall.

First we put 5 students into lecture hall and keep them in $5 \mathrm{~min}$. Then recorded their responses in that moment. After that we put another 5 students to lecture hall. At that time there were 10 students in the lecture hall and we gather the responses of those 10 students. Likewise we put 25 students to lecture hall by increasing 5 students at a time. At each condition we recorded current temperature and light intensity values in order to determine comfortable values for lecture all. Then we used those values to implement the prototype.

\section{Detect Human by Using Kinect Sensor}

In this system, human detection is not done only using human motion. It detects human by using the distance between Kinect and human using $\mathrm{X}$ and $\mathrm{Z}$ coordination given to the system.

Mostly Kinect detects human using X, Y, Z coordination. Also, Kinect can recognize six skeletons at one time and it can cognize 25 joints in skeleton. Figure 3 presents 25 joints that Kinect v 2 can recognize.

In our system, we used the head joint to detect human. Because it is the smoothest way that can recognize human by other objects in the specific area. As an example, consider the lecture hall, it has many objects, like chairs, tables, projectors, etc

From those objects Kinect can easily recognize the human head, because most other parts of body may be covered from the other objects in the lecture hall.

As mentioned before Kinect used $\mathrm{x}, \mathrm{y}, \mathrm{z}$ coordination to locate the human. To do that Kinect used its infrared sensor to locate the $3 \mathrm{D}$ points of the joints in space. The coordinate system can be described as follows. At the center of IR sensor all the $\mathrm{x}, \mathrm{y}, \mathrm{z}$ coordinates value equal to zero $(\mathrm{x}=0, \mathrm{y}=0, \mathrm{z}=0)$.

The $X$ value increased from the sensor's left. Y increases up and $Z$ direction increased its value from out of the sensor is facing. Figure 4 shows how Kinect initializing the $\mathrm{x}, \mathrm{y}, \mathrm{z}$ coordination.

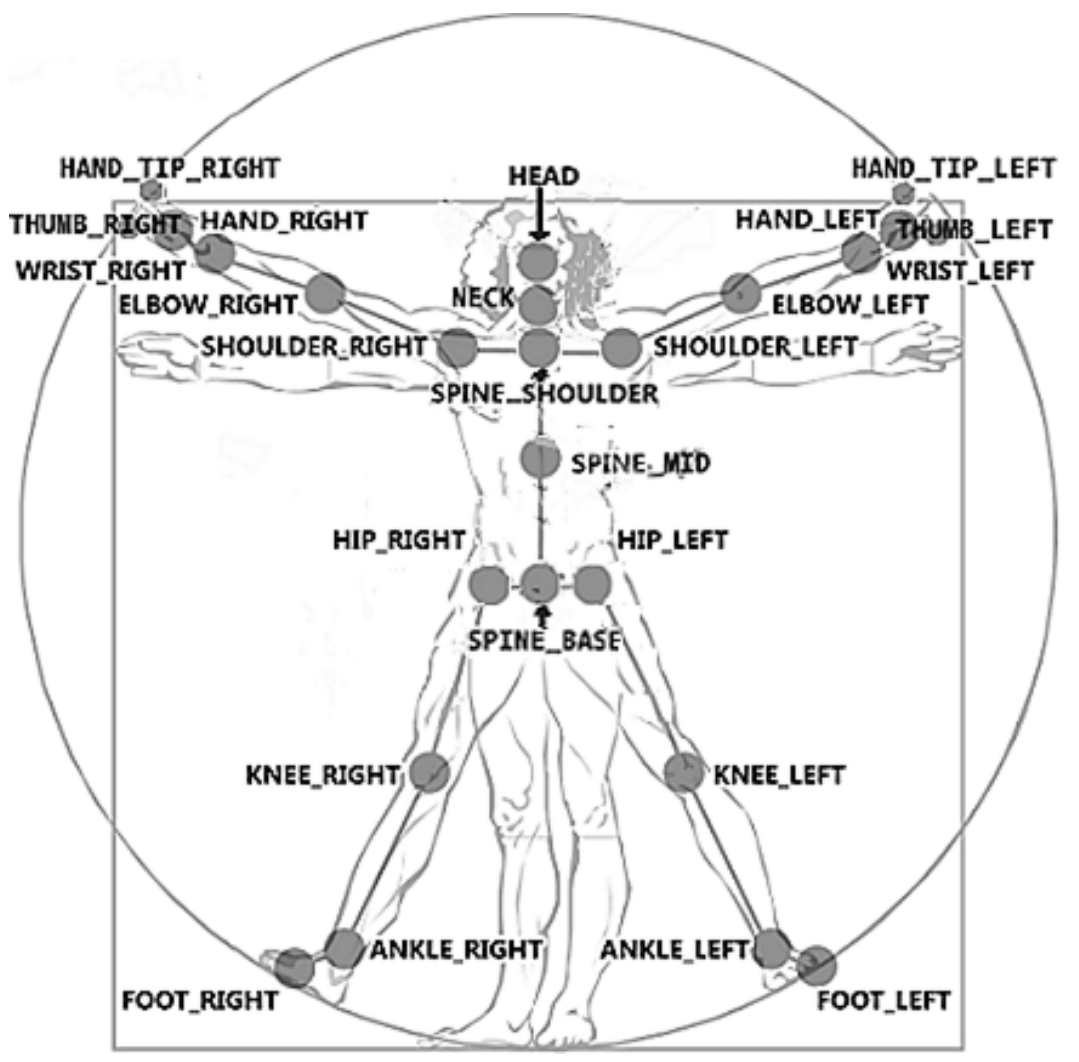

Fig. 3: Twenty five-joint skeleton 


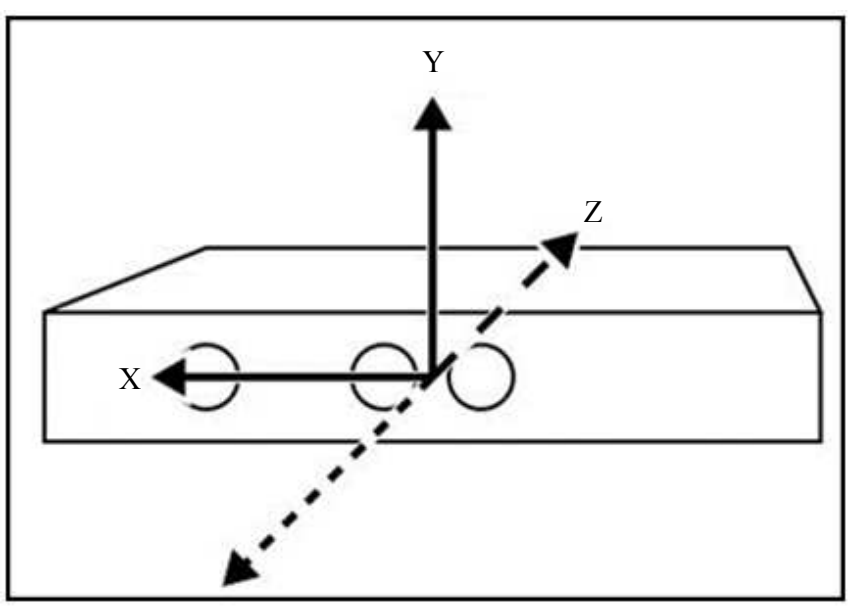

Fig. 4: Twenty five-joint skeleton

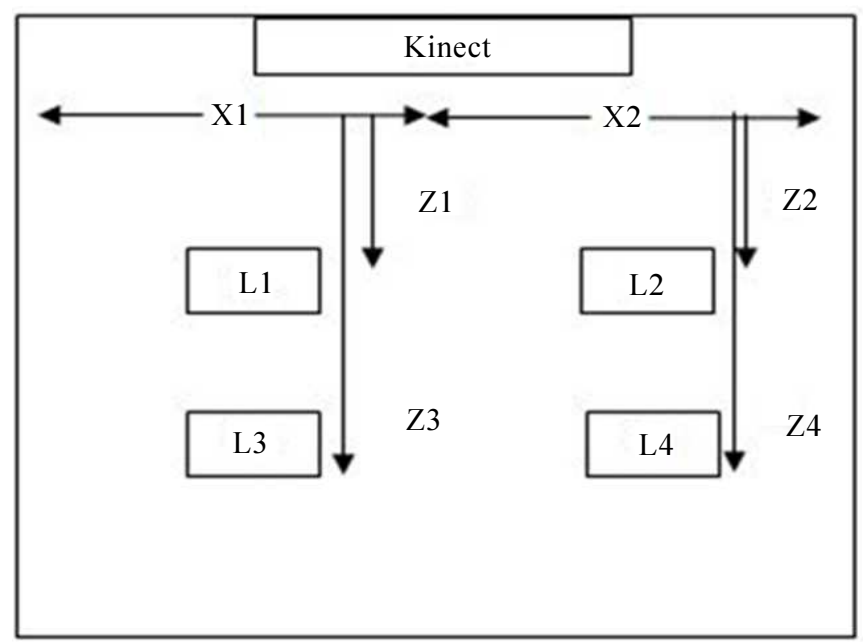

Fig. 5: Specifying place by using $x$ and $z$ coordination

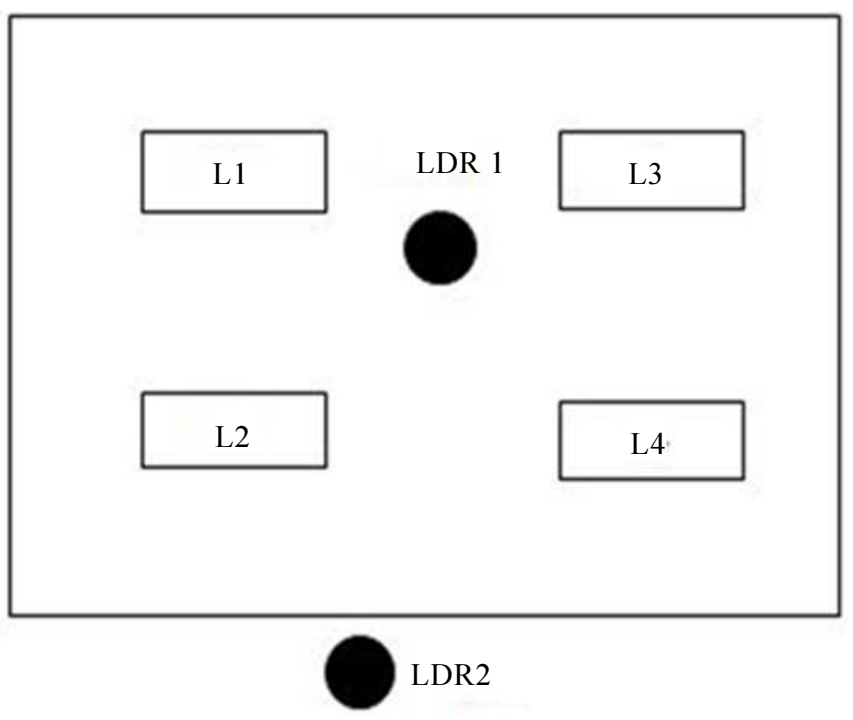

Fig. 6: LDR arrangement 


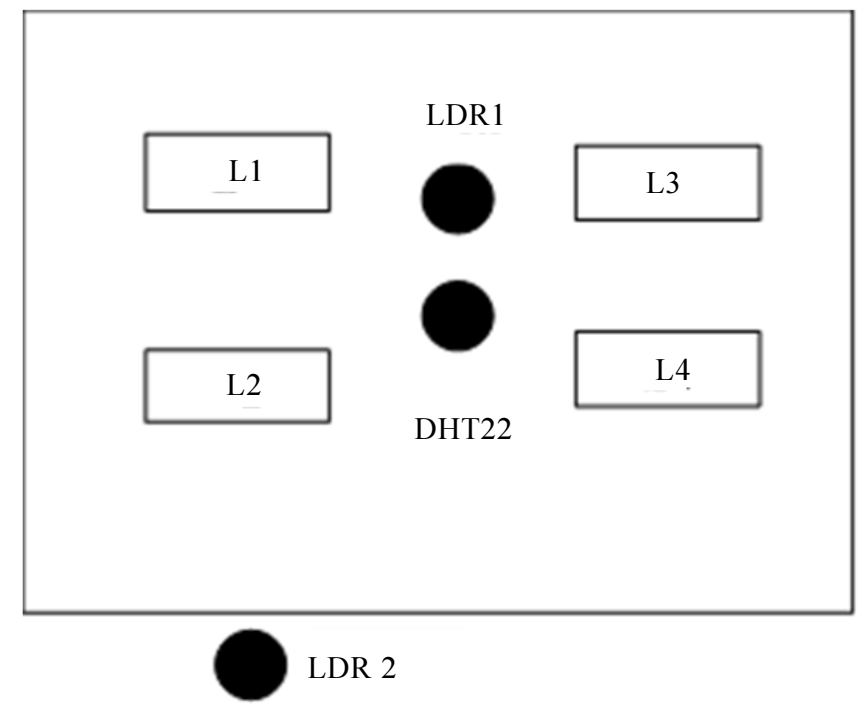

Fig. 7: DHT22 arrangement

Here we give a range of $\mathrm{x}$ and $\mathrm{z}$ coordination to Kinect to locate the electric devices in the lecture hall. Kinect program is written by using $\mathrm{CH}$ and Visual Studio 2017 used as IDE as a programming environment. Figure 5 explains how we gave the $\mathrm{x}, \mathrm{z}$ range to locate a specific device.

L1 can consider as a Light1. To locate L1, we give $\mathrm{X} 1$ and $\mathrm{Z} 1$ coordination ranges to Kinect $(\mathrm{X} 1=>0 \mathrm{~m}$ $0.5 \mathrm{~m}, \mathrm{Z} 1=>0 \mathrm{~m}-0.5 \mathrm{~m})$. When a person comes to given specific range, Kinect will inform it to the system.

Also, Kinect will be placed $3 \mathrm{~m}$ from the floor of lecture hall and it will be angled 300 downwards from its typical horizontal position. Kinect position will be at the front center of the lecture hall and it will be facing the audience.

\section{Detect the Light Intensity Using Two Ldrs}

Next step is detecting the light intensity of the human located place. We used LDR sensors to detect light intensity.

First, we take several LDR values under different conditions in the lecture hall. At the same we collect the students' responds according to the visibility. Using those responses we decide the suitable LDR value for control the lights in the lecture hall. To do that we use two LDRs.

Then we set two LDRs for specific places. One LDR is placed inside the lecture hall (centre of the lecture hall) and the other one placed in front of the entrance. Consider inside LDR is as LD1 and outside LDR is as LD2. According to the students' responses, 300lx was the threshold value that can used to control the lights on the lecture hall. If LD1 less than 3001x and LD2 greater than $3001 x$, system will provide message to open the curtains in the lecture hall. If LD1 and LD2 got greater than 300lx the same message will be displayed by the system. If LD2 less than 300lx light in a human presence areas in the lecture hall will automatically turn on. Also, the light will automatically turn off when a person leaves the place. Figure 6 display how the LDRs arranged in a lecture hall.

\section{Detecting the Temperature and Humidity Level}

To catch the humidity and temperature level of the human present place, we used the DHT22 sensor. We placed it in the centre of the lecture hall. First we take humidity and temperature values of different situation of the lecture hall (Situations are described under the topic of "Define the comfortable zone for lecture hall"). Then we programmed the sensors according to those fitted temperature and humidity levels. If temperature and humidity is higher than the given level (threshold temperature value is $29^{\circ} \mathrm{C}$ and threshold humidity level is $63.5 \%$ ), the system automatically turns on the fan or AC.

Here we used DHT 22 because it has -40 to +125 Celsius temperature measuring range and also it has +-0.5 degree accuracy. Another thing is it has 0 to $100 \%$ humidity measuring range and its accuracy is $2-5 \%$. Figure 7 shows how the DHT22 sensor is placed in a lecture hall.

\section{Receiving Real-Time Information}

With the help of IoT, System gathers all the information sent by the sensors using network connection and installs it in a database. Then using the web server it provides real-time information via the website. Given information is:

- $\quad$ Provide alert messages to action need to take ("Open the windows")

- Provide environmental condition detail of specific 
place (Temperature and humidity level)

- Provide the details about activating devices

- Provide details about not rightly working devices

- Power consumption in the lecture hall

\section{Results and Discussion}

We have been conduct questionnaire to detect suitable temperature and intensity values for lecture hall. Table 1 and 2 shows the results number of students provided in the questionnaire.

Table 1 and 2 proof that $29^{\circ} \mathrm{C}$ is the temperature that students lose their comfortable in the lecture hall. Also in intensity value of $300.611 \mathrm{x}$ is the threshold value that students have less visibility in the lecture hall.

The major objective of this research is reducing the wastage of electricity power in the faculty. As mentioned before, electricity wastage occurs mainly because of carelessness. Another reason for power wastage is not using the daylight in an effective manner. But our proposed system has the ability to overcome those problems.

Table 3 describes the problems identified in the research and solutions that research provided to each problem.
Also we found suitable number of light and fans needed according to the number of students in the lecture hall. Table 4 shows comfortable electric devices needed to live in the lecture hall.

According to the Table 4 results we can corollary that at least one fan and one light needed to be activate when one person presence in the lecture hall.

Figure 8 and 9 shows the distribution of temperature and intensity values under different condition.

According to the Fig. 8 and 9 no lights and fan condition is not comfortable for any student. Many students feel comfortable in other four conditions with one fan. As well as students visibility is turn to normal in Lights activated conditions.

In this study, we proposed a automate system for manual switching system in the Faculty of Applied Sciences, Sabaragamuwa University of Sri Lanka. The proposed system is able to reduce the wastage of electricity power. There are many existing systems that respond to human presence and control the electric devices according to that. In previous studies PIR sensor has been used to recognize the human. Problem with the PIR sensor is, it cannot recognize human without considerable motion.

Table 1: Results of temperature in different conditions

\begin{tabular}{|c|c|c|c|c|c|c|}
\hline \multirow[b]{2}{*}{ Condition } & \multicolumn{6}{|c|}{ Number of students } \\
\hline & Very hot & Hot & Normal & Cold & Very cold & Temp $\left({ }^{\circ} \mathrm{C}\right)$ \\
\hline Lights 0 Fans 0 & 0 & 23 & 2 & 0 & 0 & 29.9 \\
\hline Lights 2 Fans 1 & 0 & 3 & 22 & 0 & 0 & 29.8 \\
\hline Lights 2 Fans 2 & 0 & 0 & 24 & 1 & 0 & 29.6 \\
\hline Lights 4 Fans 1 & 0 & 10 & 13 & 2 & 0 & 29.6 \\
\hline Lights 4 Fans 2 & 0 & 0 & 22 & 3 & 0 & 29.5 \\
\hline
\end{tabular}

Table 2: Results of intensity values in different conditions

\begin{tabular}{|c|c|c|c|c|c|c|}
\hline \multirow[b]{2}{*}{ Condition } & \multicolumn{6}{|c|}{ Number of students } \\
\hline & Very high & High & Normal & Low & Very low & Inten (lx) \\
\hline Lights 0 Fans 0 & 0 & 23 & 2 & 0 & 0 & 300.61 \\
\hline Lights 2 Fans 1 & 0 & 3 & 22 & 0 & 0 & 440.68 \\
\hline Lights 2 Fans 2 & 0 & 0 & 24 & 1 & 0 & 440.68 \\
\hline Lights 4 Fans 1 & 0 & 10 & 13 & 2 & 0 & 450.83 \\
\hline Lights 4 Fans 2 & 0 & 0 & 22 & 3 & 0 & 450.83 \\
\hline
\end{tabular}

Table 3: Problems and solution of the research

\begin{tabular}{ll}
\hline Problems Identified & Solutions provided \\
\hline Wastage of daylight power & $\begin{array}{l}\text { Proposed system is provides commands to use day light power } \\
\text { when necessary. Ex: Gives message "Open the windows" }\end{array}$ \\
Wastage of electrical power due to carelessness & $\begin{array}{l}\text { Automated manual switch system } \\
\text { Automate system can prevent from power wastage due to } \\
\text { happen carelessness } \\
\text { Unnecessary cost (Huge Electricity bill) }\end{array}$ \\
$\begin{array}{l}\text { Proposed system is able to provide real-time information like } \\
\text { current working devices in a specific place, details of broken } \\
\text { devices, as well as environmental condition of given place and } \\
\text { provide alert message including tasks need to be done }\end{array}$ \\
Use Kinect sensor to detect humans.
\end{tabular}


Table 4: Comfortable electric devices according to different number of students

\begin{tabular}{lll}
\hline \# of Students & \# of Fans needed & \# of Lights needed \\
\hline 5 & 1 & 1 \\
10 & 1 & 1 \\
15 & 1 & 2 \\
20 & 2 & 2 \\
25 & 2 & 3 \\
\hline
\end{tabular}

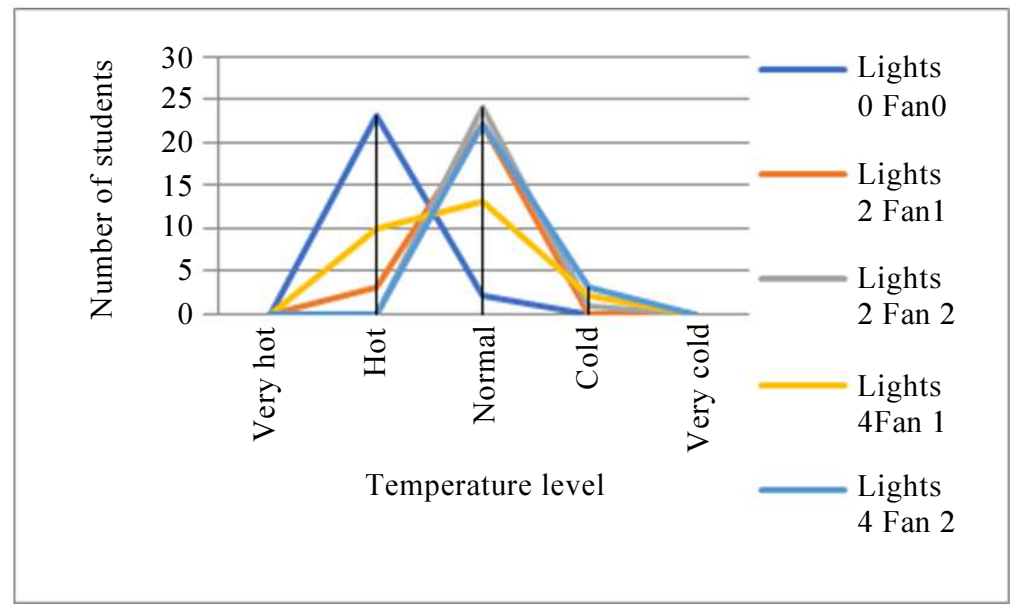

Fig. 8: Distribution of temperature

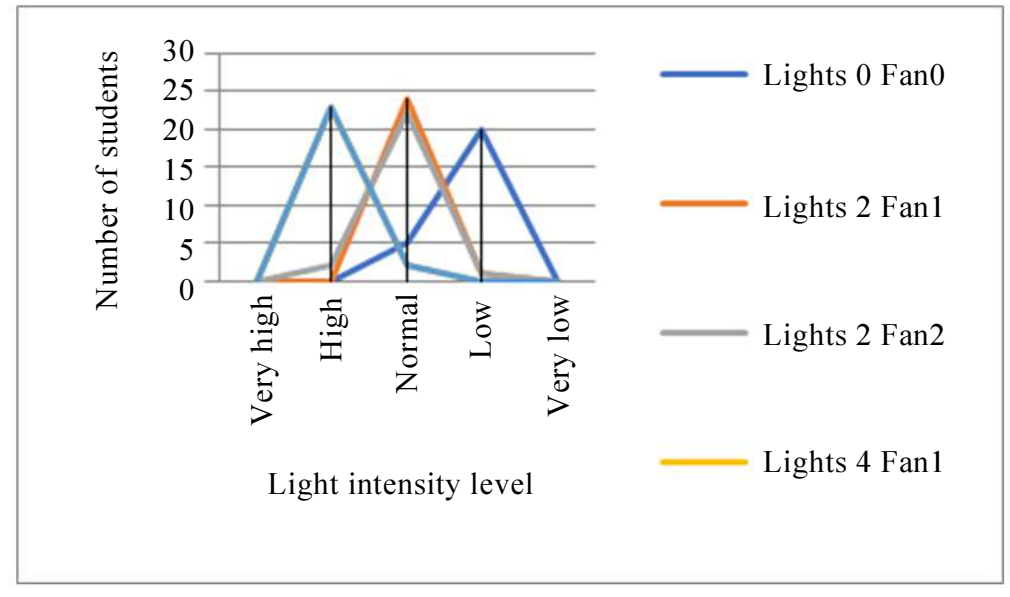

Fig. 9: Distribution of light intensity

If a person stays near the PIR sensor without movement for a long time the sensor is able to recognize human.

The proposed system has the ability to solve those problems because we used the Kinect sensor rather than the PIR sensor to detect human. Kinect recognizes human until human stay within the range of tracking of Kinect sensor. Without any motion, Kinect can recognize human by human's skeleton joints. So, Kinect sensor is the best solution for such kind of system because it is not creating the above mentioned problems.

The proposed system also provided the details about the electric devices which are in the building and environmental condition of human presence areas. It gives the working status of devices as well as the environmental details such as temperature and humidity level in a specific place. Using those details the administrative team can make decisions effectively and they can take actions as needed. It leads to improve the quality of lifestyle in university premises. As an example, proposed system can verify the devices which are not working rightly. So administrators can find out what happened there if the device is broken or whether the problem is with the electricity system such as electric power leakage or wiring problem.

According to the data which gathered form students 
we got human comfortable temperature values, light intensity values as well as number of electric devices which affect to comfortability of humans.

Usually all the lecture halls in the faculty, turn on its lights and fans from 7.00 am to $5.00 \mathrm{pm}$. So estimated power consumption of one lecture hall is $75 \mathrm{kWh}$ per day. So its power consumption for week is $375 \mathrm{kWh}$ and 18,000 $\mathrm{kWh}$ per year. Using the proposed system we hope to reduce the power consumption of lecture hall into $50 \mathrm{kWh}$ per day. It will be reduced $25 \mathrm{kWh}$ per day and we can save $60,000 \mathrm{kWh}$ per year from one lecture hall.

Ceylon Electricity Board (CEB) will charge SLR 14.65 for 1 unit from Government University in Sri Lanka. For one lecture hall it cost SLR 263, 700 for year.

After using proposed system cost will become SLR 1, 758,000 per year. So cost benefit from one lecture hall is SLR 87, 900 per year. In the faculty there were 20 lecture halls. So we can save SLR 1, 758, 000 for year after using this proposed system.

The limitation of the proposed system is that it cannot use the hall longer than $4.5 \mathrm{~m}$, because Kinect cannot detect human who stays in more than $4.5 \mathrm{~m}$.

For the future work, we hope to improve the system by using more than one Kinect for large halls. Also provide voice commands using Kinect microphones when emergency cases.

\section{Conclusion}

The proposed system is an automated system where the IoT technology is used. It has the ability to reduce the wastage of electricity. This system leads to manage and control the electric power as well as to reduce the excrescent cost. Also, that system enhanced the efficiency and effectiveness of power usage. The proposed system also has overcome the problems related PIR sensor that occurs in the previous proposed system. Using the Kinect sensor to build such kind of system is a new suggestion for the scientific community.

\section{Acknowledgement}

We pay our sincere gratitude to the academic staffs of the Faculty of Applied Sciences of Sabaragamuwa University of Sri Lanka. Further, we acknowledge Prof. Udaya Rathnayaka and the other experts who have directly and indirectly involved in order to complete the research work successfully.

\section{Author Contributions}

Shanmuganathan Vasanthapriyan: Designing of experiment (75\%), Laboratory and experiment (75\%), Interpretation and data analysis (75\%), Writing up (75\%).

Viduni Randima: Designing of experiment (25\%), Laboratory and experiment (25\%), Interpretation and data analysis (25\%), Writing up (25\%).

\section{Ethics}

The author testifies that this article is original and contains unpublished material. All ethical standards that ensure scholarly integrity have been followed.

\section{References}

Bhushan, K.P., D.B. Ravindra, L.N. Nilesh, N.S. Satish and C.P. Dinesh et al., 2018. Energy efficient smart classroom. Int. J. Res. Applied Sci. Eng. Technol., 6: 85-89.

Chaudhari, A., B. Rodrigues and S. More, 2016. Automated IoT based system for Home Automation and Prediction of Electricity usage and Comparative Analysis of various Electricity Providers: SmartPlug. Proceedings of the 2nd International Conference Contemporary Computing Informatics, Dec. 14-17, IEEE Xplore press, India, pp: 6.

DOI: 10.1109/IC3I.2016.7917995

Del Ama Gonzalo, F., J.A. Hernandez and B. Moreno, 2017. Electrical energy consumption in buildings by means of experimental measurements: Analysis of an educational facility. Proceedings of the International Conference Electrical Computing Technologies Applications, Nov. 21-23, IEEE Xplore press, United Arab Emirates, pp: 1-4. DOI: 10.1109/ICECTA.2017.8251976

Gonzalez, R.M., T.A.J. Van Goch, M.F. Aslam, A. Blanch and P.F. Ribeiro, 2014. Microgrid design considerations for a smart-energy university campus. Proceedings of the IEEE PES Innovative Smart Grid Technologies, Oct. 12-15, IEEE Xplore press, Turkey, pp: 1-6.

DOI: 10.1109/ISGTEurope.2014.7028743

Guiqing, Z., D. Xingchao, W. Ming and L. Chengdong, 2012. Controller design for the internet of things for Building Electrical Equipments. Proceedings of the Power Engineering Automation Conference, Sept. 18-20, IEEE Xplore press, Wuhan, China, pp: 1-5. DOI: 10.1109/PEAM.2012.6612515

Jabeen, A. and D.M. Kumar, 2016. Automatic Lecture hall Lighting Controller and Energy Saving based on Microcontroller Unit. IARJSET, Int. Advanced Res. J. Sci. Eng. Technol.

Jiang, G., L. Yu, Y. $\mathrm{Wu}$ and W.Z. Song, 2013. Cooperative electricity consumption scheduling and pricing for future residential smart grid. Proceedings of the 9th Asian Control Conference, Jun. 23-26, IEEE Xplore press, Turkey, pp: 3.

DOI: 10.1109/ASCC.2013.6606187.

Jin, J., J. Gubbi, S. Marusic and M. Palaniswami, 2014. An information framework for creating a smart city through internet of things. IEEE Internet Things J., 1:112-121. DOI: 10.1109/JIOT.2013.2296516. 
Ketchman, K.J., V. Khanna, K. Parrish and M.M. Bilec, 2018. Small business electricity disaggregation: Where can we improve? Towards increased transparency of appliance modal parameters. Energy Build., 176: 194-202.

DOI: 10.1016/j.enbuild.2018.07.020.

Lakra, M., K.V. Kiran and S. Chinara, 2016. Design of Smart and Intelligent Power Saving System for Indian Universities. Proc. First Int. Conference Inform. Commun. Technol. Intell. Syst., 1: 245-253. DOI: 10.1007/978-3-319-30933-0 26.

Lakra, M., K.V. Kiran and S. Chinara, 2016. Design of smart and intelligent power saving system for Indian Universities. Proceedings of $1 \mathrm{st}$ International Conference on Information and Communication Technology for Intelligent Systems: Volume 1. Smart Innovation, Systems and Technologies, Springer, Cham. DOI: 10.1007/978-3-319-30933-0 26

Lestari, D., I.D. Wahyono and I. Fadlika, 2017. IoT based electrical energy consumption monitoring system prototype: Case study in G4 Building Universitas Negeri Malang. Proceedings of the International Conference Sustainable Information Engineering Technology, Nov. 24-25, IEEE Xplore press, Indonesia, DOI: 10.1109/SIET.2017.8304161

Matsui, K. and Y. Yamagata, 2014. Design and evaluation of an electricity consumption metering and visualization system for households. Proceedings of the International Conference Utility Exhibition Green Energy Sustainable Development, Mar. 19-21, IEEE Xplore press, Thailand, Electronic.
Minoli, D., K. Sohraby and B. Occhiogrosso, 2017. IoT considerations, requirements and architectures for smart buildings-energy optimization and nextgeneration building management systems. IEEE Internet Things J., 4: 269-283.

DOI: 10.1109/JIOT.2017.2647881

Pan, J., R. Jain, S. Paul, TamVu and A. Saifullah et al., 2014. An internet of things framework for smart energy in buildings: Designs, prototype and experiments. IEEE Internet Things J., 2: 527-537. DOI: 10.1109/JIOT.2015.2413397.

Pingle, Y., S.N. Dalvi, S.R. Chaudhari and P. Bhatkar, 2016. Electricity measuring IoT device. Proceedings of the 3rd International Conference Computing Sustainable Global Development, Mar. 16-18, IEEE Xplore press, New Delhi, India.

Singh, J., S.S. Mantha and V.M. Phalle, 2018. Analysis of technical and economic electricity saving potential in the urban Indian households. Sustainable Cities Society, 43: 432-442. DOI: $10.1016 /$ j.scs.2018.09.006

The End of Fossil Fuels, 2019. Ecotricity.co.uk. https://www.ecotricity.co.uk/our-greenenergy/energy-independence/the-end-of-fossil-fuels.

Wei, M., S.H. Hong and M. Alam, 2016. An IoT-based energy-management platform for industrial facilities. Applied Energy, 164: 607-619. DOI: 10.1016/j.apenergy.2015.11.107 